\title{
Social Determinants of Health: Approach to Address the Underlying Socio-economic Disparities
}

\author{
Acharya $\mathbf{P}^{1}$ \\ ${ }^{1}$ People's Health Movement (PHM), Nepal
}

\section{Background}

Inequality in health is the result of complex interaction between individual, cultural, political, economic factors. Each and every factor may act equally and independently but those factors usually demonstrate the interdependent and collective interactions on the determination of the health status of people.

Social status of people determines the exposure to different risk factors like occupational hazards, it also influence the access to medical interventions and this also creates the variation on the health care seeking behavior of people. These factors are not only governing the health but they also reflect the overall status of people like: the socio-political power they have, the productivity they can achieve and the freedom they can enjoy. Those factors are collectively recognized as the social determinants of health. (1)There are some preferred social determinants that need to be addressed for the betterment on the health status of the people and these factors are (but not limited to) the relationship between labor, management, and government; social security for the needy people; the social and political ideologies of the state; access to the health resources and peoples' participation on decision making. (2)

If any segment of the society is isolated from the quality health care services on the basis of any characteristics like: race, ethnicity, gender, sexuality (including sexual orientation and identity), disability, age, and, although not always recognized as such, social class then this will result in the disparities in the health status of the people in that society. Unfortunately, such discrimination are almost everywhere, irrespective of how developed the country is or how much economic progression has the country made. (3)

There are some examples which explain the excruciating disparities in health and survival at the international and intra-national level. People in the poorest areas will, on average, die seven years earlier than people living in the richest neighborhoods. (4) A child born in Nepal is twelve times more likely not to live till his or her fifth birthdaycompared to a child born in Thailand. (5) Within India, children born in the poorest $20 \%$ households are more than three times as likely to die before their fifth birthday compared to children in the richest $20 \%$ households. (5) Skilled birth attendance, an important determinant of maternal mortality, is less than 5\% among the poorest $40 \%$ women in both Bangladesh and Nepal. (5)

This paper aims to assess the inequality in health status from the socio-economic perspective. This also seeks to quickly review the struggle by the international community to tackle the barriers to the universal access for health services mainly the neoliberal policies.

\section{Discussion}

From the studies in more than 10 countries over a decade of period during 1980s, the World Health Organization concluded that the inequality in the health status is continuously increasing. It has been mostly recognized that the root causes of inequalities in health are the complex interaction between personal economic, political and environmental factors. (6)

Various level of inequality exists in South East Asian Region both in intra and international level.Within-country health inequities are dramatic, except in Sri Lanka and Thailand, even though in all countries economic growth has been generally strong and improvements in overall levels of health are visible. (7)

Access to health service is a key intervention that can reduce social inequalities in health outcomes. Countries that provide universal access to primary health care have smaller inequalities in most health outcomes (Maldives, Sri Lanka and Thailand). (5) Universal access is achievable at low incomes and without heavy expenditures on health and that depends on how the state wants to protect or promote the health right of the people, one remarkable example may be Sri Lanka. It has demonstrated a tremendous achievement in the expansion of Primary Health Care Services in spite of the deprived economic circumstances. (8)

The response of the state towards the health rights of its citizens is probably the strongest factor which has deep impact on the health of the citizens. "Health system" of a country officially defines the view of the state towards the health of its citizens. Health system is the political approach and it usually reflects the conceptualization of health and role of the state in guaranteeing and providing it to the citizens. (4) Significance of the health system in the orientation of health as a social right or a commercial product can be best illustrated by the following diagram.

CORRESPONDENCE : Pawan Acharya, People’s Health Movement (PHM), Nepal. Email: ac.pawan@gmail.com 


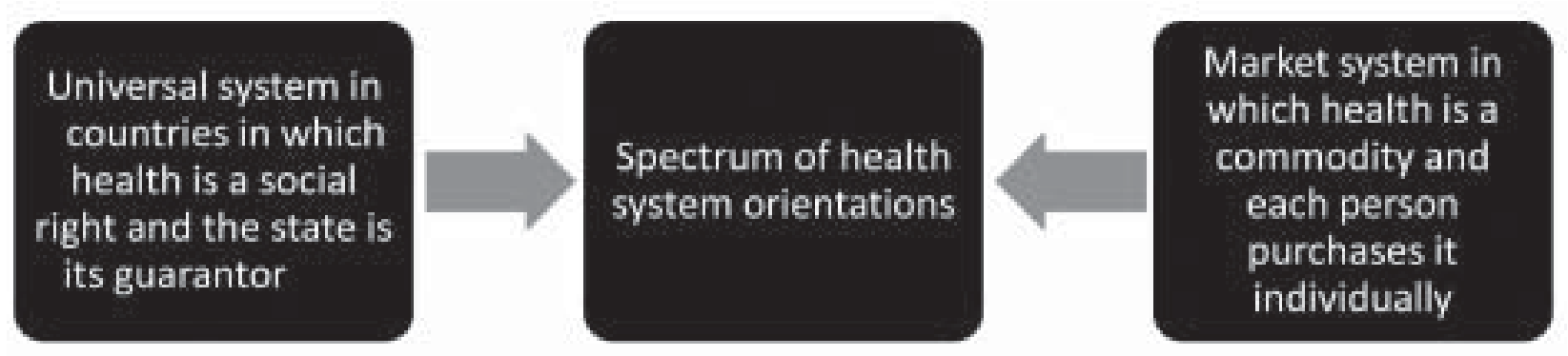

Source: Venezuelan Health Reforms; 2008. (4)

Socio-political ideology of the state devises the health and social system of the country. Those policies and systems are generally influenced by the global economic forces or macroeconomic policies.

In many countries, neoliberal intervention or health care reform had shown a devastating effect on the health status of people by commercializing their right to the health services. It is preventing the people to utilize and enjoy the primary health care services.Empirical data from eight developing country revealed that the subsidy on the health care expenditure and the proper method of distribution of subsidy among different class of people may influence the out-ofpocket spending by the particular class of people. (9) It is because when a government accepts the neoliberal economic policies, it will obviously have the economic policies dominate the social welfare policies. The main thrust of liberal economic policies is to just regenerate wealth from the capital investment. There is no value for well being.One of the main features of neoliberal globalization is the concentration of capital and increase in the inequality and poverty. (10) Free flow of capital is rocketing the economic growth but only for those who are able to make a huge amount of capital investment. Study conducted in Latin America found that the larger companies involved in the health care marketing were the major beneficiaries of the health care reform/ neoliberal intervention on the health services. (11) Later on, WHO realized that the political process of involvement of such companies always favored for the capital investment and it violates the fundamental human right of the people by visualizing the health and social services as a commercial commodities. (11) The ultimate sufferer will be the people who can't pay for themselves. Therefore it is continuously widening the gap and deteriorating the health status of the poor people.This is also significant to Nepal. In Nepal, The rural poverty and the gross inequality in the economic status of the people within the country signify the inequalities in the health status of people. (12)

Some extraordinary efforts had been produced to define the healthy or unhealthy people as thebiological unit embedded in the complex socio-cultural matrix. The marvelous achievement was the Alma-Ata Declaration and genesis of primary health care. It has identified the multidimensional nature of health and illness and also has respected the holistic model of health. (7) It had recognized that the factors besides health has crucial role to play in health status of people. It has committed that disparities in the health status of people on the basis of any characteristics is socially and politically unacceptable. The Primary Health Care strategy is still a huge challenge to those who just want to prescribe the drugs and promote the sophisticated technological interventions. In spite of the series of continuous attacks on the primary health care, it was able to gain attention and trust of people due to its magical impacts on their health. It showed some beautiful results in the shaping the health status of peoplein Cuba and Tanzania. (8)

Radicals and experts of public health who were against the disparities among the health status of people among their socio-economic status were always fighting to make Comprehensive Primary Health Care (CPSC) survived. (13) With the main objective to support the countries and global health partners to address the social factors leading to ill health and health inequalities, WHO launched the Commission on Social Determinants of Health in 2005. (14) The commission urged all the state and non state parties including health activities to share their hands to flourish the global movement to address the inequality in the health status of people within and between the countries. It embarked that disparity in the health status is the issue of social justice.

\section{Conclusion}

There are different factors besides the bio-medical intervention that determine the health status of people. Some factors are still to be identified and defined, that's why we believe that health is multidimensional and dynamic. Social policies, equity, people's participation, interaction between state, service providers and citizens are crucial to determine the health status of people. In the present context, something is going wrong in the interaction between those factors and the disparity is continuously increasing. Overtaking the health and social welfare policies by the economic policies just for the sake of capital increment is not just annoying it is intolerable. The social determinants approach shows that the biomedical or therapeutic interventions alone could not produce any significant effect on the health status of people. To create a healthy society we must correct the underlying factors which are responsible for widening the gap between 
the health status of people. The worst of this increasing gap is seen in the pattern of mortality, oh the other hand weshould not forget the pain and suffering of the people due to the morbidity. Therefore we have to realize health from an alternative perspective, and that can be best explained by the social perspective i.e. social determinants of health. We have to admire health not just as the service but rather a complex interaction of people, resources and social policies. People deserve better than this, we deserve better health.

\section{REFERENCES}

1. Narayanan R, Narayanan T. From Alma-Ata to Rio: health for all to all for equity WHO South- East Asia Journal of Public Health. 2012;1(1):4-7.

2. Starfield B. Are social determinants of health the same as societal determinants of health? Health Promotion Journal of Australia. 2006;17(3):170-73.

3. Krieger N. Embodying inequality: a review of concepts, measures and methods for studying healht consequences of discrimination. International Journal of Health Services. 1999;29(2):295-352.

4. Feo O. Neoliberal policies and their impact on public health education: Observation on the Venezuelan experience. Social Medicine. 2008 November 2008;3(4).

5. Revitalizing Primary Health Care. Jakarta: WHO Regional Office for South-East Asia2008 August.

6. Crombie IK, Irvine L, Elliott L, Wallace H. Closing the Health Inequalities Gap: An International Perspective. 2005 ed. Europe: World Health Organization; 2005. p. 3.

7. Joarder T, Islam A, Uddin A. Revitalizing Health for All: Developing a Comprehensive Primary Health Care Model For Bangladesh. Bangladesh: JAMES P GRANT SCHOOL OF PUBLIC HEALTH, BRAC UNIVERSITY2011.

8. WHO. Actions on the Social Determinants of Health: Learning From Previous Experiences. Geneva: World Health Organization Secretariat of the Commission on Social Determinants of Health; 2005. p. 12-5.

9. Inequalities in health care use and expenditure: emprical data from eight developing countries and countries in transition. Bulletin of the World Health Organization. 2000;78(1).

10. Coburn D. Beyond the income inequality hypothesis: class, neo-liberalism, and health inequalities. Social Science and Medicine. 2004;58(2004):41-56.

11. Armada F, Muntaner C, Navarro V. Health and Social Security Regorm in Latin America: The Convergence of the World Health Organization, The World Bank and Transnational Corporations. International Journal of Health Services. 2001;31:729-68.

12. Makinen M, Waters H, Rauch M, Almagambetova N, Bitran R, Gilson L, et al. nequalities in health care use and expenditure: emprical data from eight developing countries and countries in transition. Bulletin of the World Health Organization. 2000;78(1).

13. Joarder T, Islam A, Uddin A. Revitalizing Health for All: Developing a Comprehensive Primary Health Care Model for Bangladesh: James P Grant School of Public Health, Brac University2011 April 30, 2011.

14. Baum F, Simpson S. Building healthy and equitable societies: What Australia can contribute to and learn from the Commission on Social Determinants of Health. Health Promotion Journal of Australia. 2006;17(174-9). 